\title{
A CRITICAL REVIEW OF RADIOCARBON DATING OF A NORSE SETTLEMENT AT L'ANSE AUX MEADOWS, NEWFOUNDLAND CANADA
}

\section{REIDAR NYDAL}

\author{
Radiological Dating Laboratory, The Norwegian Institute of Technology
} Trondheim, Norway

\begin{abstract}
Recent progress in high-precision calibrations of radiocarbon dates has led to evaluations of earlier research. This has been the case with dates from the Norse settlement at L'Anse aux Meadows which was discovered by Helge Ingstad in 1960. The most problematic feature of this series up to now was the use of sample material which partly derived from driftwood. The present paper concludes that charcoal from this site demonstrated no greater errors than normal from other settlement sites. With an assumed total systematic error of 30 \pm 20 years, as a mean for various tree rings, the calibrated age range of L'Anse aux Meadows is $\mathrm{AD} 975-1020$. This agrees well with the assumed historical age of ca $\mathrm{AD} 1000$, a result which has also been recently corroborated by high-precision accelerator dating at the University of Toronto.
\end{abstract}

\section{INTRODUCTION}

A Norse settlement in Canada was discovered by Helge Ingstad in 1960 who previously set forth the theory that Canada must have been discovered earlier than the discovery of America by Columbus. His theory derived from careful study of the Icelandic sagas, and extensive experience from Spitsbergen, Greenland and Arctic Canada. The Icelandic sagas (Groenlendinga saga, ca AD 1190, and Erik's saga, ca AD 1260) describe several expeditions ca AD 1000 to a land named Vinland, which Ingstad assumed must be found somewhere on the coast of Canada (Fig 1).

The settlement was discovered at L'Anse aux Meadows at the northern tip of Newfoundland. From 1961 to 1968, Ingstad made seven archaeological expeditions to the site, during which his wife, Anne Stine Ingstad (1977), directed the archaeological work. According to archaeological assessment, the excavated houses were Norse and similar to types in Iceland and Norway from ca AD 1000 . The most convincing proof of Norse origin came from artifacts of the Viking age, such as a stone lamp, a spindle whorl and a bronze pin.

Radiocarbon dating from L'Anse aux Meadows was performed at the Trondheim Radiocarbon Dating Laboratory during the excavation period. From a selected number of 16 samples, mainly deriving from charcoal, a mean age was calculated for the site (Nydal, Lövseth \& Syrstad, 1970; Nydal, 1977). More satisfactory agreement with the assumed historical age was obtained from Stuiver and Pearson's (1986) calibration curve (Nydal, 1983).

The results of the L'Anse aux Meadows series have been disputed, not only because of the possibility of systematic error due to driftwood, but also because of the selection of certain samples in the calculation (Waterbolk, 1971; Campbell, 1980). Since the dating was done 25 years ago, the know- 


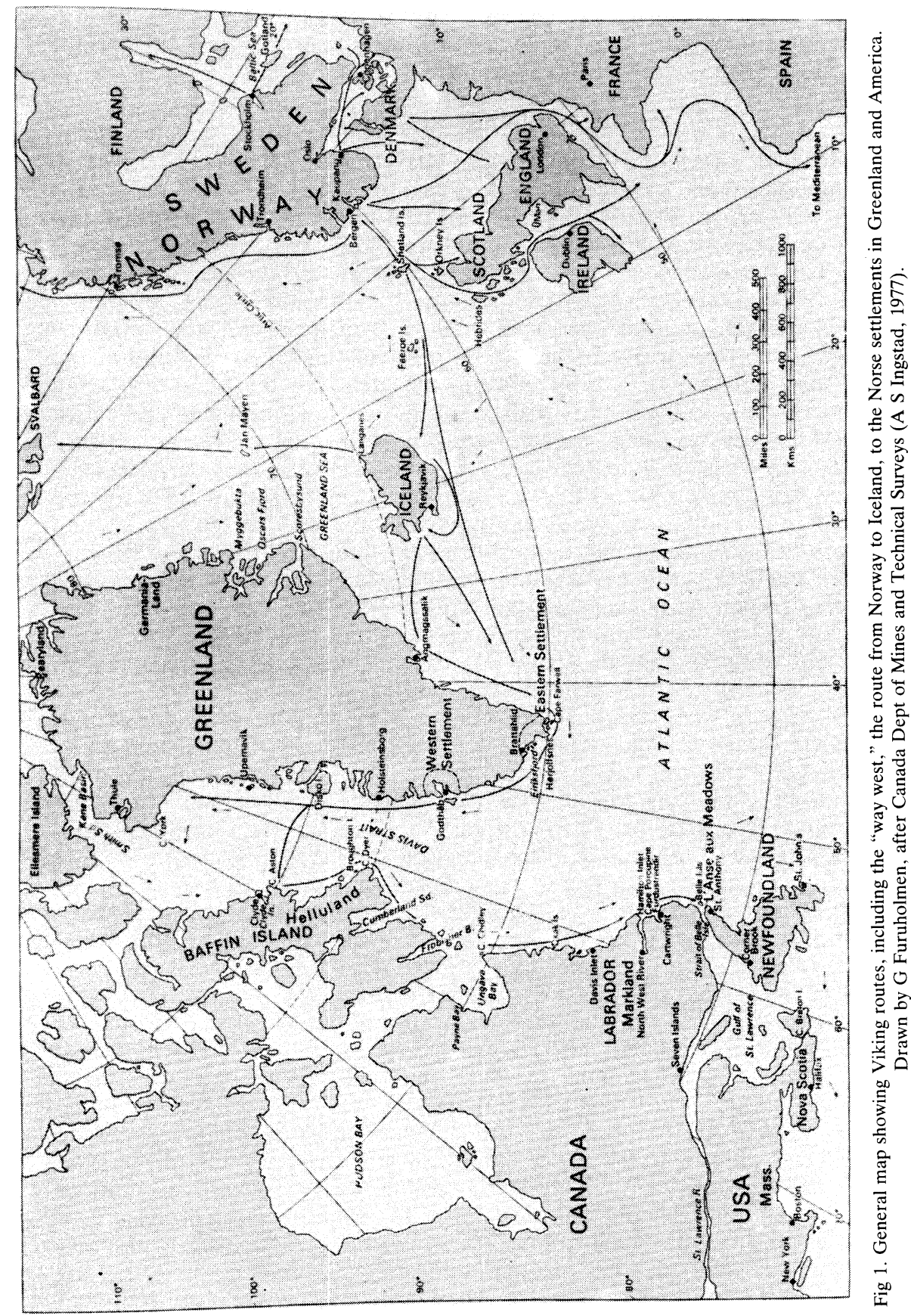


ledge about error sources and accuracy of calibration has increased, and a fresh look into previous dating results was deemed necessary. It is also interesting to compare our results with those of the Isotrace Accelerator Laboratory at the University of Toronto (Beukens, 1986).

\section{THE RADIOCARBON SAMPLES}

Most of the samples from L'Anse aux Meadows were charcoal from cooking pits. Even though systematic errors may occur in the samples, it is a great advantage to know that the charcoal really derives from fire produced by the settlers. Discussion about magnitudes of possible systematic errors has, until now, mainly focused on driftwood as a most reasonable source of error. According to Helge Ingstad, driftwood is found along the coast of Canada in great quantities, mainly brought in with the Labrador current. According to Paulssen (1977), most of the charcoal found at the house sites is from vegetation found in the area, but there are also some species that are only found further south, in Newfoundland and Nova Scotia. Such species (Tilia, Quercus and Pinus strobus) are the main proof that driftwood occurs in the charcoal. At times, driftwood may dramatically affect a dating result. For example, the wood can be frozen into drift ice and circulate in the polar ice cap for many years before it is freed by ice melting at lower latitudes. After that time, the wood will either drift ashore or sink. The drifting time in the ocean is unimportant because most wood sinks after a couple of years. In special cases, such driftwood could have been found on shore and used for fuel. Storage time on the shore may also be a source of error, but for a settlement which lasted some years, the charcoal would probably contain recently arrived driftwood.

Freshly cut wood may also be a source of systematic error in charcoal. This is due to the fact that charcoal derives from wood which covers a variable range of tree rings. The outer ring of a tree represents the last growth before death; this ring will give the most correct historical age. In dating inner rings, we must correct for the difference in age between these rings and the surface of the tree. Charcoal in a pit should represent a mixture of fragments, ranging from a few rings from the surface of a tree to rings from the inner part of greater logs. The mean systematic error caused by the influence of unknown tree rings may, of course, vary, depending on the vegetation in various pits. Bakker, Vogel and Wislanski (1969) discuss such errors in the range of $10-50$ years under various circumstances.

In addition to 13 charcoal samples from well-defined house sites, there are 2 other samples (T-410, -411) from outdoor cooking pits. There are also 4 peat samples and 1 sample of whale bone. The peat samples are from house walls which, according to Henningsmoen (1977), were built by piling various types of sod on top of each other. Depending on the thickness of the turf and rate of growth, the age of the turf may be several hundred years too old. In other cases, the age may be too young because of roots from more recent vegetation. Rootlets can remain in the samples after pretreatment and affect the result, which can also be affected by humic acid from overlying younger layers. Earlier pretreatment of peat consisted only of boiling with $1 \mathrm{M} \mathrm{HCl}$ to remove carbonates. The samples received no pretreatment with $\mathrm{NaOH}$ to remove humic acid. 


\section{MEASUREMENT AND CALIBRATION}

Of a total number of 20 samples from L'Anse aux Meadows, it soon became clear that not all samples yielded ages representative of the settlement. In previous research (Nydal, Lövseth \& Syrstad, 1970; Nydal 1977, 1983), 16 samples were used to calculate a mean age for the settlement. The calculation was based on 13 charcoal samples from house sites, 2 peat samples (T-530, -531) from house walls, and 1 whalebone sample (St-2665).

In reconsidering the dating result at L'Anse aux Meadows, I find it most reliable to base a mean-age calculation on the first 13 charcoal samples (Table 1). These samples were all found in charcoal pits in houses. Even considering systematic errors due to driftwood and old logs, the results (Table 1, Fig 2) show no dramatic deviations in single samples that could be referred to as extreme cases of driftwood. Taking into account the relatively small number of samples, the agreement with a Gaussian distribution is

TABLE 1

${ }^{14} \mathrm{C}$ dates from L'Anse aux Meadows

\begin{tabular}{|c|c|c|c|c|}
\hline Sample no. & Location & Material & ${ }^{14} \mathrm{C}$ dates (BP) & Cal dates $(\mathrm{AD})^{*}$ \\
\hline $\mathrm{T}-310$ & House A & Charcoal & $1310 \pm 130$ & $620-880$ \\
\hline T-306 & House B & & $1210 \pm 110$ & $670-960$ \\
\hline T-309 & House C & & $1240 \pm 130$ & $660-950$ \\
\hline $\mathrm{T}-364$ & House D & & $1050 \pm 70$ & $900-1020$ \\
\hline $\mathrm{T}-324$ & House E & & $1130 \pm 70$ & $810-990$ \\
\hline $\mathrm{T}-325$ & House F, II & & $1080 \pm 70$ & $890-1020$ \\
\hline $\mathrm{T}-326$ & House F, IV & & $1250 \pm 70$ & $670-880$ \\
\hline $\mathrm{T}-327$ & House G & & $870 \pm 70$ & $1040-1250$ \\
\hline $\mathrm{T}-366$ & Smithy, J & & $1090 \pm 90$ & $880-1020$ \\
\hline T-393 & Smithy, J & & $890 \pm 70$ & $1030-1230$ \\
\hline $\mathrm{T}-367$ & Charcoal kiln & & $1130 \pm 70$ & $810-990$ \\
\hline $\mathrm{T}-368$ & Cooking pit 1 & & $1170 \pm 90$ & $720-980$ \\
\hline $\mathrm{T}-365$ & Cooking pit 2 & & $1140 \pm 90$ & $780-990$ \\
\hline $\mathrm{T}-410$ & Outdoor pit & & $450 \pm 90$ & $1410-1490$ \\
\hline $\mathrm{T}-411$ & Outdoor pit & & $890 \pm 90$ & $1010-1150$ \\
\hline $\mathrm{T}-530$ & $\begin{array}{l}\text { House A } \\
\text { Southern wall }\end{array}$ & Peat & $950 \pm 90$ & $990-1190$ \\
\hline $\mathrm{T}-531$ & $\begin{array}{l}\text { House } F \\
\text { Northeast wall }\end{array}$ & & $950 \pm 50$ & $1010-1150$ \\
\hline $\mathrm{T}-817$ & $\begin{array}{l}\text { House D } \\
\text { Top wall }\end{array}$ & & $1300 \pm 70$ & $650-780$ \\
\hline $\mathrm{T}-818$ & $\begin{array}{l}\text { House A } \\
\text { Northern wall }\end{array}$ & & $1320 \pm 80$ & $640-770$ \\
\hline St-2665 & House F, III & Whale bone & $1040 \pm 110$ & $1010-1220$ \\
\hline
\end{tabular}

${ }^{*}$ Calibrated according to Stuiver and Pearson (1986) 


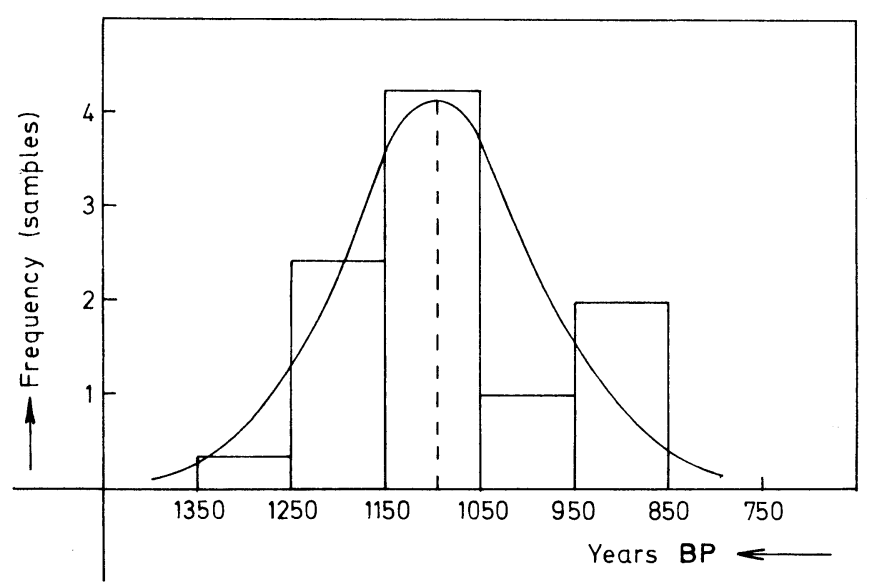

Fig 2. Histogram based on 13 charcoal samples from L'Anse aux Meadows compared with a Gaussian distribution

more satisfactory with pure charcoal than in the previous calculation (Nydal, 1977). Also, there is either a systematic error of about the same magnitude in all samples or there are no important systematic errors at all.

As for the other samples (T-410, -411, $-530,-531,-817,-818)$ in Table 1 , there are reasons to exclude them from the calculation of the mean age of the settlement, even though some may support the assumed historical age. Samples T-410 and -411 were found in outdoor cooking pits at the shore. According to A S Ingstad (1977), we cannot exclude native use of these pits. The age range of T-410, AD 1410-1490, is also far from an age related to the Norse settlement. The relation of the 4 peat samples to the settlement is well documented, but the result reveals various magnitudes of systematic error. The oldest samples, T-817 and -818 (AD $650-780$ and 640 -770 , respectively) are certainly contaminated by old peat. On the other hand, contamination seems to have had an opposite effect on the result of samples T-530 and -531, even though they are closer to historical prediction.

The whalebone sample, St-2665, could have been an excellent material if the collagen fraction had been used. This early dating was, however, based on the total organic fraction, with the possibility of contamination. Also, lack of information about correction for reservoir effect and isotopic fractionation renders the result, $A D$ 1010-1220, doubtful, even though the assumed historical age is within the range.

\section{MEAN AGE FOR THE SETTLEMENT}

The average ${ }^{14} \mathrm{C}$ result, based on the 13 charcoal samples, is $1090 \pm 22$ BP. The error limit is one standard deviation, and is derived from the counting result. This theoretical error seems smaller than the error $( \pm 35 \mathrm{yr})$ measured from the scatter of data, and indicates that there are errors other than the purely statistical ones. A truer historical age is found by calibration. 
Figure 3 shows the calibration of the result from L'Anse aux Meadows (van der Plicht \& Mook, 1989). The ${ }^{14} \mathrm{C}$ distribution of the mean result of 13 charcoal samples is seen along the vertical axis. This Gaussian distribution shows a dramatic change after calibration, as we see a very
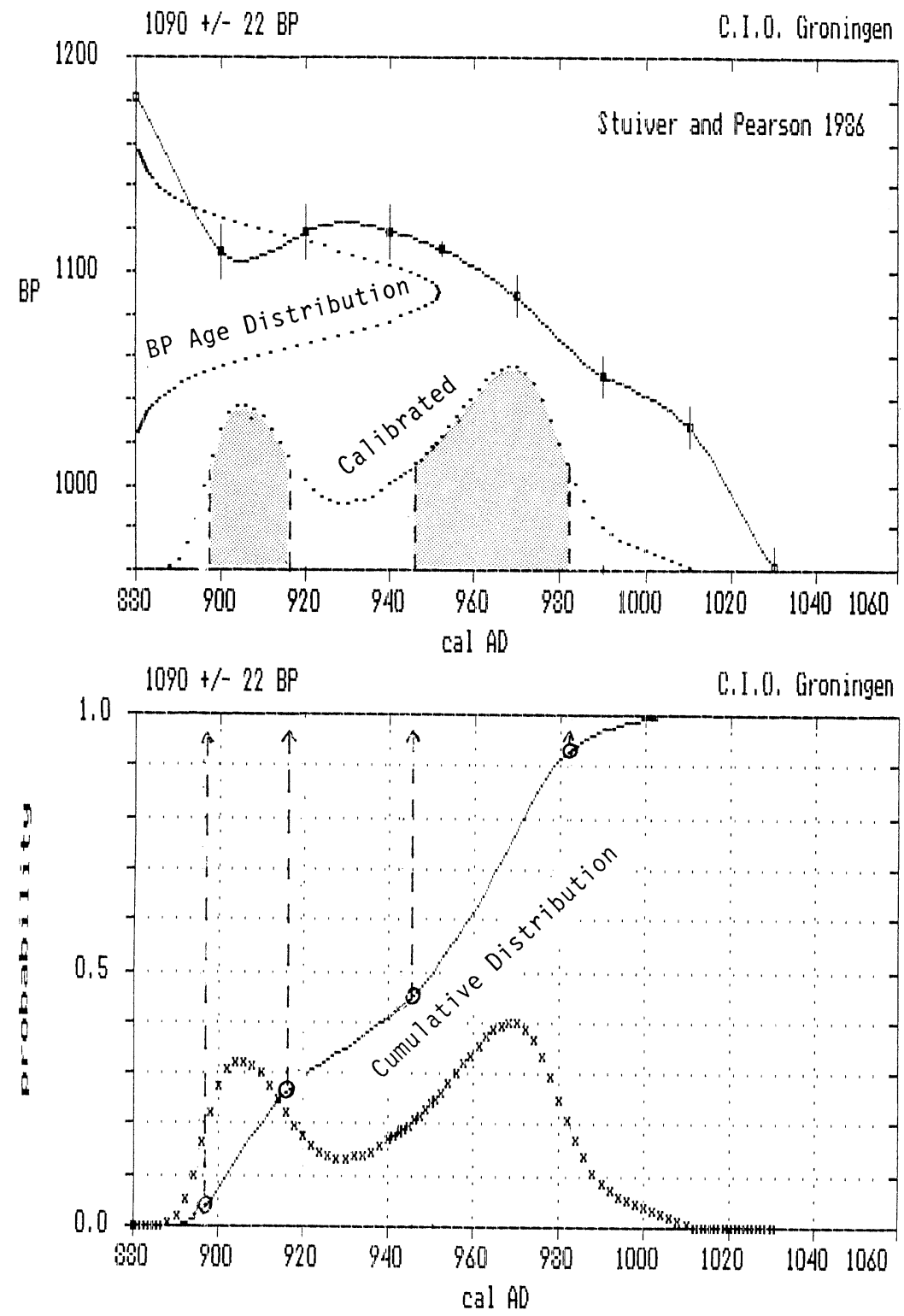

Fig 3. Calibrated date based on 13 charcoal samples from L'Anse aux Meadows 
irregular part of the calibration curve. According to the ${ }^{14} \mathrm{C}$ result, $1090 \pm$ $22 \mathrm{BP}$, and the cumulative result (Fig 3), the highest probability for the age $(68 \%)$ is found within two peaks, one in the range AD 898-916 and the other (with greater probability) at AD $946-982$.
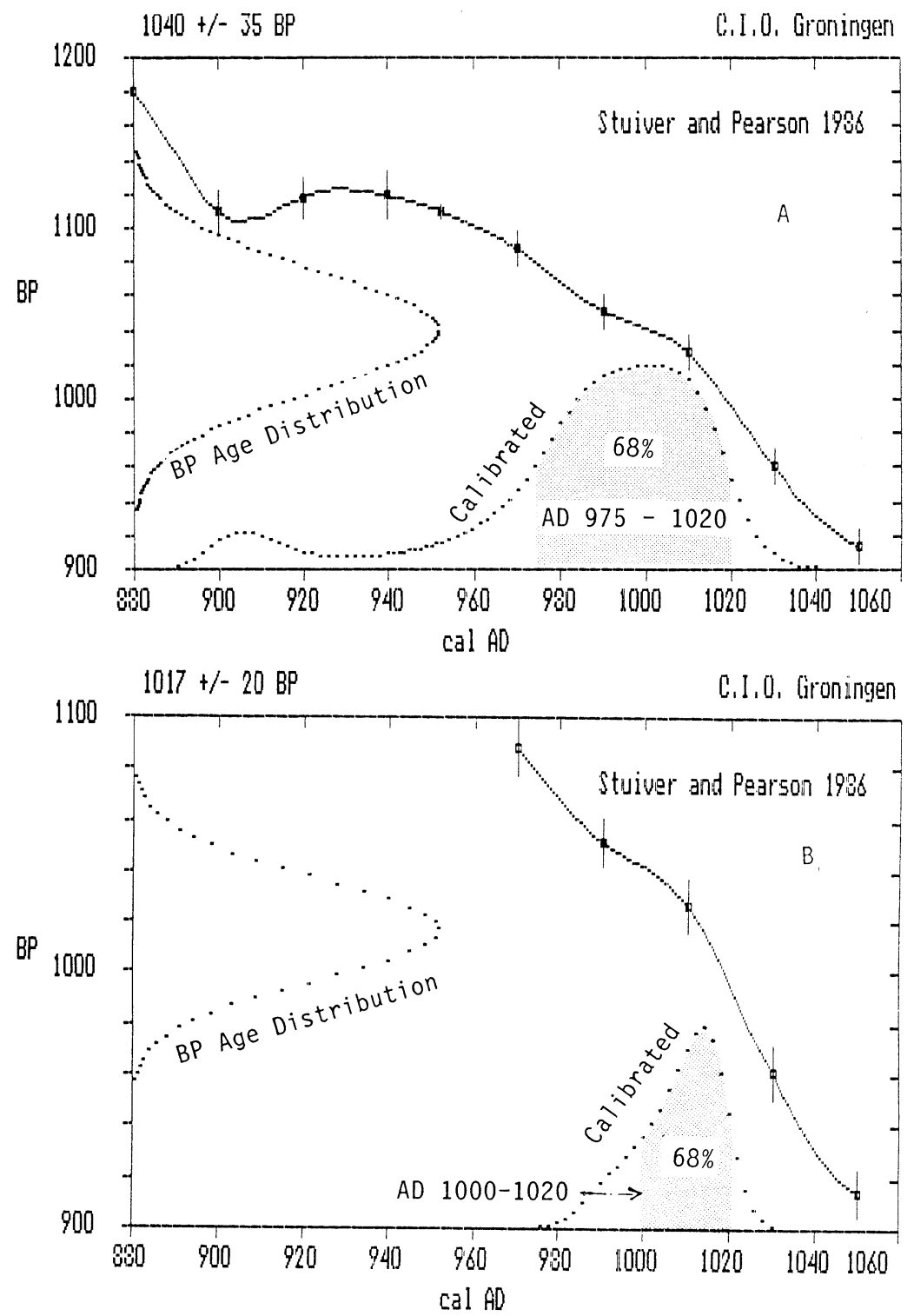

Fig 4. Calibration of dates from L'Anse aux Meadows; A. Calibrated Trondheim measurements; B. Calibrated Toronto measurements 
In the discussion about systematic error due to charcoal, there is little evidence for large errors due to driftwood, but only to a systematic error from a mixture of charcoal from wood of various tree rings. Considering the experience of Bakker, Vogel and Wislanski (1969) for such samples, we may assume a systematic error of $30 \pm 20$ calendar years. Because of the linear shape of the calibration curve in the actual region, this implies a change in the ${ }^{14} \mathrm{C}$ age to $1040 \pm 35 \mathrm{BP}$. The error limit, calculated from the scatter of data, also includes the scatter of systematic errors appearing in the charcoal. The calibrated age from L'Anse aux Meadows is now found in the range $\mathrm{AD} 975$ - 1020, with a maximum peak at ca $\mathrm{AD} 1000$ (Fig 4A).

\section{THE TORONTO MEASUREMENT}

Beukens (1986) measured four L'Anse aux Meadows samples using accelerator mass spectrometry (AMS). The samples were carefully collected by Parks Canada, who is now in charge of the site, to avoid systematic errors. Their objective was to find wood that had been associated with metal tools, which were not used by indigenous people. The samples were collected from a cultural layer containing wood chips, charcoal fragments, artifacts and twigs. Sample TO-116 consisted of the outer portion of a partly charred stick, $1.5 \mathrm{~cm}$ in diameter, TO-117 and -118 consisted of twigs, and T119 came from the outer rings of a tree stump. All but the first sample (1440 \pm 50 ) yielded representative ages, $1030 \pm 50,990 \pm 30$, and $1040 \pm 30 \mathrm{BP}$, respectively, which Beukens calibrated to a mean age of AD $997 \pm 8$. With his choice of samples, Beukens directly reached a nearly linear part of the calibration curve and obtained a well-defined age with a very low error limit. Beukens' result changes slightly, however, when applying the same representation as for the Ingstad samples. From a mean age of $1017 \pm 20 \mathrm{BP}$ based on 3 samples, the calibrated age is now found in the range, AD 1000 -1020 (Fig 4B).

\section{SUMMARY AND CONCLUSION}

${ }^{14} \mathrm{C}$ dating for L'Anse aux Meadows was performed in Trondheim during the excavation of the site from 1961 to 1968 . Recent advances in calibration and ${ }^{14} \mathrm{C}$ technology has made re-evaluation necessary. A recalculated mean age of the settlement is now based on 13 charcoal samples found in well-documented house sites. After considering possible systematic errors, the calibrated age is in the range AD $975-1020$, calculated with an accuracy of $68 \%$. Driftwood as a possible source of error seems to have a negligible influence on the result.

A separate suite of three wood samples from a cultural layer were recently dated in Toronto with AMS, for which a mean calibrated age ranged from $\mathrm{AD} 1000-1020$. A combined result from Toronto and Trondheim (Fig 5) yielded a mean ${ }^{14} \mathrm{C}$ age of $1023 \pm 17 \mathrm{BP}$ with the following calibrated result:

$68 \%(1 \sigma)$ AD $1000-1018$

$95 \%(2 \sigma)$ AD $986-1022$ 
With this highly accurate measurement, a historical event at ca AD 1000 is even more strongly supported. The ${ }^{14} \mathrm{C}$ date is presented with a certain probability distribution in a range, and the result cannot be used to pinpoint a definitive expedition. There is a probability of $68 \%$ that the occupation occurred between $\mathrm{AD} 1000-1018$ and $95 \%$ from $\mathrm{AD} 986-1022$. Even though the statistics account for only $5 \%$ probability of an occupation outside the latter range, we are also aware of the possibility that, for such high-precision dating, even small and unknown systematic errors may slightly change the result.

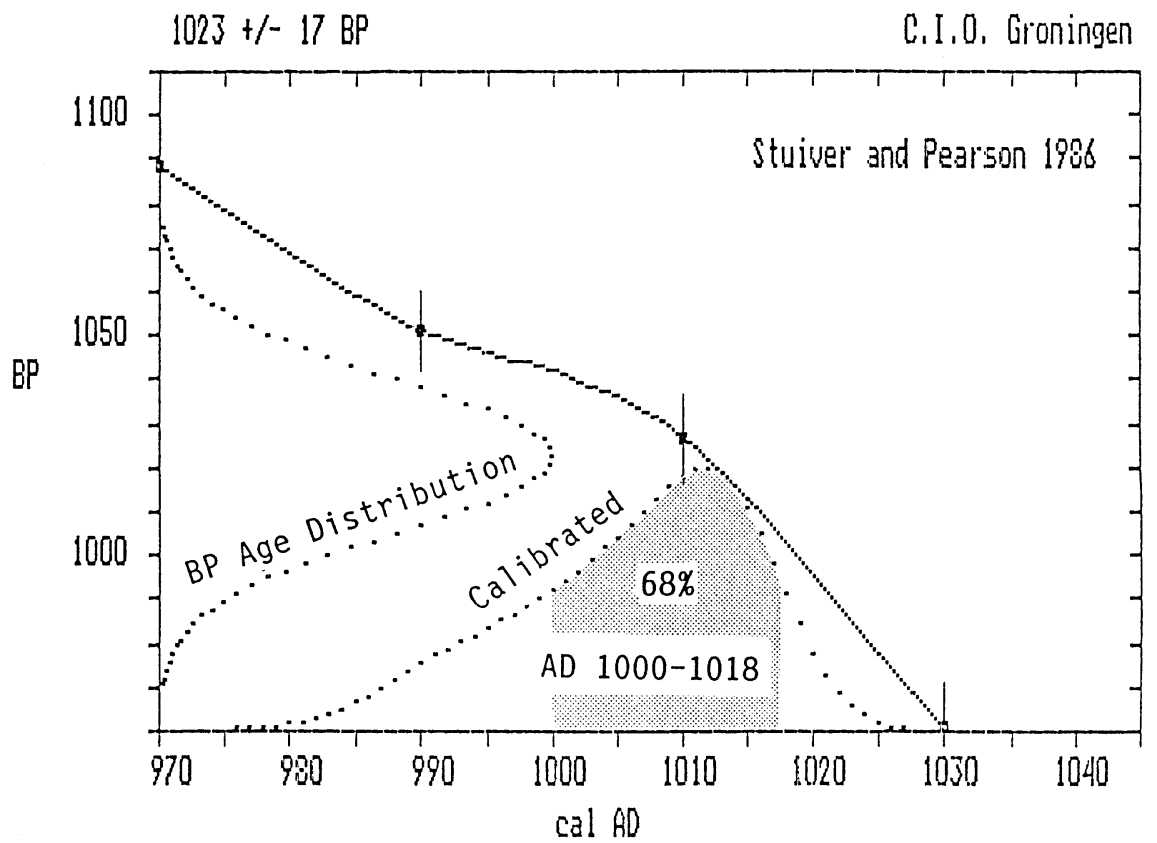

Fig 5. Mean calibrated result of the Toronto and Trondheim measurements from L'Anse aux Meadows

\section{ACKNOWLEDGMENTS}

The author thanks the following persons for helpful discussion in preparing this paper: Steinar Gulliksen, Trondheim, Johannes van der Plicht, Groningen, Marion Scott, Glasgow and John Vogel, Pretoria. Sincere thanks to Anne Stine and Helge Ingstad, Oslo, for friendly cooperation during several years. Financial support from The Norwegian Research Council for Science and the Humanities (NAVF), Oslo is gratefully acknowledged. 


\section{REFERENCES}

Bakker, J A, Vogel, J C and Wislanski, T, 1969, TRB and other C14 dates from Poland (Pt A): Reprinted from Helinium, v IX, p 327.

Beukens, R P, (ms) 1986, High precision ${ }^{14} \mathrm{C}$ dates of the L'Anse aux Meadows site: Paper presented at Canadian Archaeol Assoc, Toronto (Isotrace internal rept).

Campbell, J G, 1980, Review of Ingstad, A S, The discovery of a Norse settlement in America: Saga-Book, Viking Soc, v XX, pt 3, p 218-244.

Henningsmoen, K, 1977, Pollen-analytical investigations in the L'Anse aux Meadows Area, Newfoundland, in Ingstad, A S, ed, The discovery of a Norse settlement in America: Oslo, Norway, Norwegian Univ Press, p 289-340.

Ingstad, A S, 1977, The discovery of a Norse settlement in America: Oslo, Norway, Norwegian Univ Press, $480 \mathrm{pp}$.

Ingstad, H, 1985, Historical background and the evidence of the site at L'Anse aux Meadows: Oslo, Norway, Norwegian Univ Press, $550 \mathrm{pp}$.

Nydal, R, 1977, Radiocarbon dating of material from L'Anse aux Meadows, Newfoundland, in Ingstad, A S, ed, The discovery of a Norse settlement in America: Oslo, Norway, Norwegian Univ Press, p 341-356.

1983, Optimal number of samples and accuracy in dating problems, in Internatl symposium, ${ }^{14} \mathrm{C}$ and archaeology, 1st, Proc: Strasbourg, PACT, p 108-122.

Nydal, R, Lövseth, K and Syrstad, O, 1970, Trondheim natural radiocarbon measurements V: Radiocarbon, v 12 , no. 1 , p 285-237.

Paulssen, L M, 1977, Identification of charcoal finds, in Ingstad, A S, ed, The discovery of a Norse settlement in America: Oslo, Norway, Norwegian Univ Press, p 357-372.

Plicht, van der, J and Mook, W G, 1989, Calibration of radiocarbon ages by computer: Radiocarbon, this issue.

Stuiver, M and Pearson, G W, 1986, High-precision calibration of the radiocarbon time scale, $\mathrm{AD} 1950-500 \mathrm{BC}$, in Stuiver, $\mathrm{M}$ and $\mathrm{Kra}, \mathrm{R} \mathrm{S}$, eds, Internatl ${ }^{14} \mathrm{C}$ conf, 12 th, Proc: Radiocarbon, $v 28$, no. 2B, p 805-838.

Waterbolk, H T, 1971, Working with radiocarbon dates: Prehist Soc Proc, v XXXVII, pt 2, p 15-33. 